\title{
Maintaining Morale during Organizational Change in the Growing Entrepreneurial Firm
}

\section{Conference Paper}

Author(s):

Kaehr Serra, Caroline; Thiel, Jana

Publication date:

2018

Permanent link:

https://doi.org/10.3929/ethz-b-000283899

Rights / license:

In Copyright - Non-Commercial Use Permitted

Originally published in:

Academy of Management Proceedings 2018(1), https://doi.org/10.5465/AMBPP.2018.246 


\title{
MAINTAINING MORALE DURING ORGANIZATIONAL CHANGE IN THE GROWING ENTREPRENEURIAL FIRM
}

\author{
CAROLINE KAEHR SERRA \\ McGill University \\ JANA THIEL \\ ETH Zurich
}

\section{INTRODUCTION}

One of the most challenging crossroads for an entrepreneurial firm arrives when the managerial structures initiated at founding are no longer adequate to support its further development (e.g., Boeker \& Wiltbank, 2005; Haveman \& Khaire, 2004; Wasserman, 2003). Firms at this defining point in their evolution have been referred to as "threshold firms" (Daily \& Dalton, 1992). In order to successfully pass this evolutionary threshold, founders or other stakeholders must initiate a professionalization process, which typically comes with changes to hierarchical relations, new levels of decision authority, as well as increased functional specialization and formalized rules and procedures (Colombo, Rossi-Lamastra, and Matassini, 2015). Often, the organizational restructuring is accompanied by handing over leadership to a professional manager (Boeker and Karichalil, 2002; Wasserman, 2003).

Prior studies have shown that leadership succession increases the sense of disruption and executive turnover intention (Friedman \& Saul, 1991). So, it is certainly not surprising that many threshold firms struggle or fail altogether to professionalize and subsequently exhibit a lack of performance (Daily \& Dalton, 1992; He, 2008). Yet, the literature is surprisingly scant on the managerial aspects of that process. Despite having increased our understanding as to which features of the organizational design are critical for sustained growth, the extant research (refer to DeSantola and Gulati, 2017 for a recent review) has not tackled the question how a change in any of these features can be managed effectively while minimizing the disruption for the young firm - a gap we aim to address in this paper.

\section{THEORETICAL BACKGROUND}

Research on organizational design of threshold firms has often focused on the constraining aspects that early logics of organizing impose on the firm (e.g., Beckman \& Burton, 2008; Gedajlovic et al., 2004; Hannan \& Burton, 2002; Sine, Mitsuhashi, \& Kirsch, 2006; Zahra $\&$ Filatotchev, 2004). As the firm evolves, these constraining forces will experience pressure toward change. One of the most visible manifestations of growth-induced organizational change is the replacement of the founder-CEO with a professional CEO, typically mandated by institutional investors (Wasserman, 2003). This replacement marks a key event in the evolution of the entrepreneurial firm and has consequently received heightened attention in the literature (e.g., Boeker \& Karichalil, 2002; Boeker \& Wiltbank, 2005; Hellmann \& Puri, 2002; Minichilli et al., 2014; Wasserman, 2003), with mixed results: in many cases, the envisioned benefits of professionalization through a leadership change do not materialize ( $\mathrm{He}, 2008)$.

Strong inertial forces are at play, which are commonly a result of imprinting by the founding conditions of the firm (Stinchcombe, 1965). Founders in particular, and the systems 
they create, profoundly imprint the values and culture of the entrepreneurial firm (e.g., Baron \& Hannan, 2002; Fauchart \& Gruber, 2013; Hambrick, 2007; Johnson, 2007). In fact the firm's codes of conduct, i.e. roles, administrative procedures and decision processes, have commonly emerged through agreements and enacted practices among the founding team or the single founder and their first hires. Subsequently, behaviors and their underlying rationales become deeply ingrained and form the essence of how the organization is structured and how decisions are made. Organizational change then requires questioning those early agreements and frames of reference: important conversations must be held, and individuals must not only adapt their behaviors but also understand why those new behaviors and decision structures are required.

Prior research has shown that typical companions of such fundamental change are decreases in company morale and disenchantment, leading to employee turnover and loss in overall firm performance (Baron et al., 2001; Friedman \& Saul, 1991). However, the existing literature on professionalizing threshold firms has remained largely silent about the contribution of organizational members and their cognitive adaptation. This is surprising, as past research on organizational change has discussed the importance of interpretive schemes and individual-level cognitions (e.g., Bartunek, 1984; Bartunek et al., 2006; Greenwood \& Hinings, 1996; Pettigrew, Woodman, \& Cameron, 2001). So, in order to understand how threshold firms professionalize successfully, we believe it is necessary to examine the ability of organizational members to cognitively address the evolution of the firm. Furthermore, understanding key mechanisms to steer the change and development of behavioral schemata will add an important piece to our comprehension of growth-induced evolution and the performance of entrepreneurial firms.

\section{METHOD}

We used an inductive multiple-case design (Eisenhardt, 1989) to analyze the change in cognitions in the professionalization process of entrepreneurial firms. Our research setting is a confluence of the high-tech industry, which allows us to connect our insights to prior research on organizational blueprints (Baron et al., 1996; 1999, 2002). We employed purposive sampling (Miles \& Huberman, 1994) as we selected firms from the "Technology Pioneers" of the World Economic Forum (WEF). Since 2007, the WEF's Technology Pioneer program recognizes earlystage international technology-based companies that are likely to have an impact on business and society. Each year, 30 entrepreneurial firms have been selected to participate in the "Technology Pioneer" program, leading to a total population of 150 entrepreneurial firms at the time of our study. From the available pool of candidates, we selected firms that experienced an intentional replacement of the founder-CEO by a professional CEO in the year prior to or during the year of the study. This assured that the event was sufficiently recent, so we could minimize recall bias. In order to provide a comparable context, we further narrowed the sample to firms that were venture capital backed and located in Silicon Valley. While operating in the same ecosystem, our firms still exhibited different specific succession outcomes, which added useful variance and allowed us to distill important patterns change. Our final sample consisted of six entrepreneurial firms active in data mining, mobile payment, healthcare software, the virtual marketplace, social media marketing, and software testing.

We gathered data through semi-structured interviews with C-level team members and investors and complemented those with archival materials, including media and corporate presentations. The archival sources helped triangulate points made by our informants; leading us to believe that there were negligible levels of individual bias. We also collected data on the 
evolution of employee satisfaction from Glassdoor - an online database of company reviews. Glassdoor prompts respondents to anonymously rate their satisfaction on four aspects of a company, which we used as our measure for the performance outcome and proxy for company morale, a prime driver in change performance (e.g., Baron et al., 2001; Friedman \& Saul, 1991). For each of our sample firms, we calculated a satisfaction score the year prior to the succession event and one year after the succession took place. This allowed us to compute the change over the course of the succession, which we use in our discussion of change catalysts further below.

We began our examination and interpretation by writing case histories of the succession process for each entrepreneurial firm. Both researchers independently reviewed the transcripts and notes (Miles \& Huberman, 1994) and initially performed the open coding (Strauss \& Corbin, 1997), in which we analyzed each transcript with the goal of identifying organizational design schemes before and after the succession event, and change patterns thereof. We developed a large number of first-order categories that identified potentially relevant factors (Gioia et al., 2013). In a second step, we discussed the first-order categories with the aim of developing second order themes. We then moved on to evaluating each case individually according to the identified second-order themes before comparing their changes and discussing initial differences. For example, both authors evaluated the degree of change from nascent to mature logic of organizing in each case based on a three-fold categorization scheme (low-medium-high) that was previously used in qualitative research on entrepreneurial firms (e.g., Hallen \& Eisenhardt, 2012; Jaskiewicz et al., 2015). Subsequently, we turned to cross-case analysis in which we iteratively identified possible relationships between our codes within and across cases and existing research. Through this process, we developed our model of nascent and mature logics of organizing.

\section{FINDINGS}

Our research generated findings along two important lines: (1) the specification of two distinct logics of organizing, allowing for a clear demarcation between a non-professionalized and a professionalized firm, and (2) differences in change catalysts and their configuration in relation to the transition outcome (employee satisfaction and cognitive change). In the following, we describe each set of findings that contributed to our overall model as depicted in Figure 1.

Insert Figure 1 about here

\section{Images of Organizational Logics}

As we studied the images held by organizational members about the logics of organizing, we found that these images differed under different levels of organizational maturity along three dimensions: behavioral boundaries, goal-setting frames, and power hierarchies.

Nascent logics. Prior to the professionalization, the boundaries of organizational behavior were open and defined by the discretionary judgment of individual actors. Many team members in our sample reported that they were doing what they thought was best and needed, without designated roles to inform and restrict their behavior. Team members often created their own roles based on skills and preferences, which resulted in a culture of contribution based on own 
vision and not necessarily coordination of actions with others. On the part of goal setting and hierarchy, we found the founder to be dominating. Actions undertaken were often analyzed through the viewpoint of the founder's personal goals - even to the extent that members of our case companies considered the founder's emotions as key in their decision making process. Likewise, we observed the strong tendency towards centralization of decision making at the level of the founding CEO. Some of our respondents mentioned "hallway conversations" or "just popping by the office" as a means to get the CEO's buy-in. The founder served as the ultimate ruling authority for everything. In some cases, members of entrepreneurial teams felt that they were not able to speak their minds and that they had reservations about offering their honest opinion. Furthermore, our analysis reveals that some team members felt that a founder actively tried to limit the influence of other decision-making parties, such as for example the board.

Mature logics. Consistent with prior research on organizational design (Blau, 1972; Sine et al., 2006), we saw that the professional CEO typically attempted to install clear role assignments with explicit task profiles and responsibilities. Under mature logics, official role requirements rather than personal judgment served as the cognitive reference for action. A "sense of ownership" was deemed crucial to delivering on a role and being held accountable for actions. It also prevented extra-role behavior; individuals began to constrain their own behavior based on their shared understanding about the content and importance of their roles. On the part of goalsetting frames, a standardized goal-setting process replaced personal convictions of the founder. In our interviews, the entrepreneurial team members talked about their objectives taking a backseat vis-à-vis the requirements of the firm. Finally, in terms of power hierarchy, we also saw marked differences between nascent and mature logics of organizing. Most interviewees noted that upon the arrival of the professional CEO, regular management meetings were held and all members could speak up and be heard. Often, for the first time, the entrepreneurial team felt that there actually was a board - as a monitoring and supporting partner - that valued and required transparency and two-way communication regarding what was going on in the firm.

\section{Change Catalysts and Transition Outcomes}

As discussed previously, changing organizational design and the underlying logics may become difficult. We observed that some companies in our sample seemed to fare better at embracing this ongoing change than others. In particular, it appears that two change catalystscognitive change readiness and founder legacy treatment - varied in our sample firms.

Cognitive change readiness refers to beliefs and attitudes of entrepreneurial team members regarding the extent to which changes are needed and thus anticipated. This is closely related to constructs such as 'sense of urgency', for example, which was previously introduced by Nadler and Tushman (1989) in corporate reorientation processes. In fact, several of our entrepreneurial teams noted that they actually sensed that something had to happen, and hard facts of deteriorating financial performance or the non-attainment of goals highlighted the need for change. This sense of change readiness, however, was not the same across all our cases. Some of the teams were actually very surprised by the arrival of a professional CEO. A second change catalyst was founder legacy fairness under the professional CEO. In some cases, the professional CEO appreciated what the founder created and treated what the founder and team had built with respect. Such CEOs emphasized the importance of the groundwork the founder had laid and how, based on a change in leadership, what the team had built could turn into 
something even bigger. On the other end of the continuum, we observed firms in which the professional CEO insisted that if the company wanted to move forward there was no way to continue anything related to the founder. Instead of acknowledging the legacy of the founder as a key building block of the current company, it was viewed as something that needed to be erased. This was largely perceived as disrespectful towards key members of the entrepreneurial team and led to feelings of fear and disruption.

We found that a combination of these two catalysts made a difference in the overall transition outcomes. Some of the threshold firms displayed a high degree of change along all three dimensions, whereas other companies had only minimal cognitive changes after the new CEO took office. Table 1 below summarizes the different degrees of change that we observed in our sample firms and complements those differences with the levels of the change catalysts and the evolution of employee satisfaction.

Insert Table 1 about here

Those firms with high levels of cognitive change and high levels of change catalysts also displayed high satisfaction levels. This group (Heimdall and Nanna) basically represents a model transition; whereas the last case in our table (Odin) epitomizes the exact opposite. Here, cognitive shift hardly took place, accompanied by a marked absence of cognitive change readiness in conjunction with dismissive treatment of the founder's legacy. Between those two extremes were firms with moderate degrees of change in their cognitions (Balder, Freyr, and Frigg), which exhibited more complex and varied configurations, resulting in either marginal improvements or reductions in satisfaction levels.

Overall, we conclude that high degrees of cognitive change accompanied by high levels of change catalysts typically result in high levels of satisfaction with the newly emerging organizational blueprint. On the flipside, low degrees of cognitive change accompanied by low levels of change catalysts will result in low levels of satisfaction with the newly emerging organizational blueprint. Importantly, the strong presence of one change catalyst can offset lower levels of another change catalyst, resulting in higher satisfaction with the new organizational blueprint, although the images of organizational logics likely undergo only moderate changes.

\section{DISCUSSION AND CONCLUSION}

With our research, we illustrate the managerial complexity of the professionalization process of entrepreneurial threshold firms and provide more detailed insight into the role and structure of cognitive frames that accompany the organizational change. In so doing we hope to increase the understanding of key processes and challenges in growing the entrepreneurial firm, in particular to what extent the ability or inability of constituents to handle growth cognitively plays into outcomes of entrepreneurial ventures.

Studies of new ventures and the specifics of start-up processes often focus exclusively on single founder cognitions. However, non-founder constituents are also important contributors to the entrepreneurial process. If you will, the second act of the firm, its re-birth as a professional and mature player in the market place, entails the re-creation of an entity that is distinct from its founders. Simply replacing an incumbent founder with a new leader is unlikely to lead to 
success: organizational maturity does not follow automatically the structural re arrangements. It requires key constituents of the threshold firm to change and agree upon thought models regarding how the threshold firm is run. A failure to change logics-related cognitions will result in key constituents continue to engaged in the same behaviors that might have been useful in gaining traction in the early stages of the firm, yet limit its further evolution and growth.

In pointing to variation in the pathways that an entrepreneurial leader can take to manage complex organizational transition processes, our research provides further impetus for configurations research, which has only recently received more attention in the entrepreneurship and strategy literature (e.g., Gruber et al., 2010). With a deeper understanding of different organizing frames and how they shape the actions of the organizational members and the resulting structures of an entrepreneurial firm, future research can enhance the battery of managerial practices that make venture leaders and growth entrepreneurs more successful.

\section{REFERENCES AVAILABLE FROM THE AUTHORS}

FIGURE 1.

\section{Cognitive levers in changing organizational blueprints}

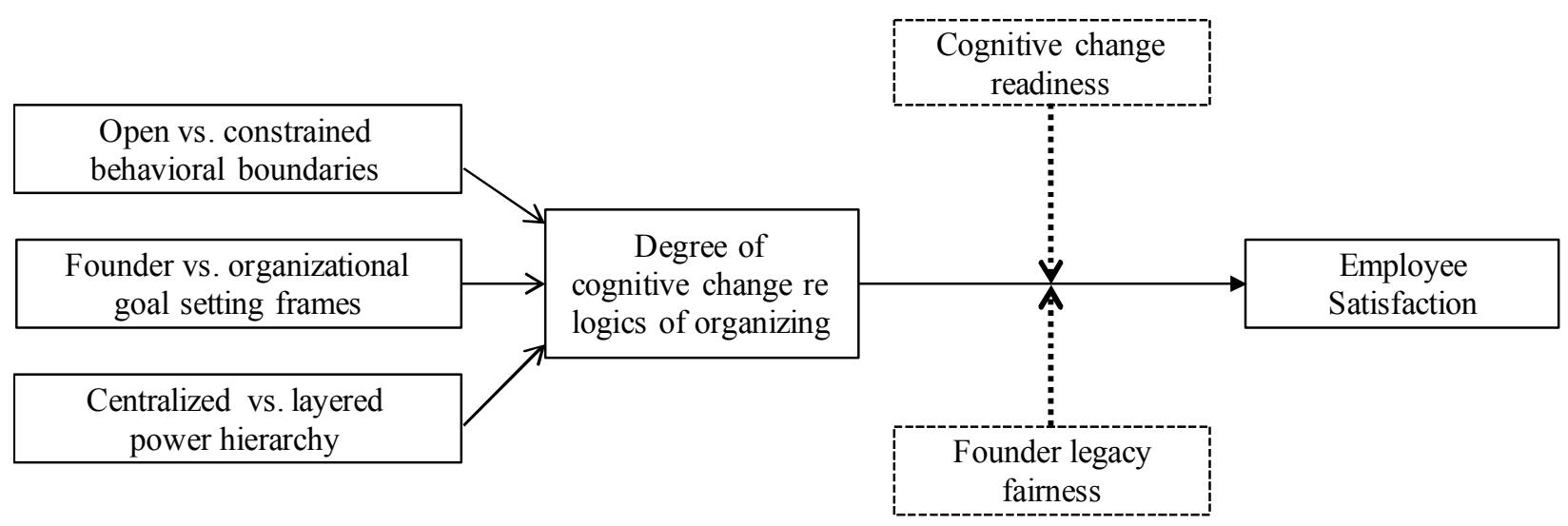

TABLE 1

Configurations of logics and change catalysts with resulting employee satisfaction levels

\begin{tabular}{|c|c|c|c|c|c|c|}
\hline & \multicolumn{3}{|c|}{ Degree of change } & \multicolumn{2}{|c|}{ Change catalyst levels } & \multirow{2}{*}{$\begin{array}{l}\text { Evolution in overal } \\
\text { employee } \\
\text { satisfaction }\end{array}$} \\
\hline & $\begin{array}{l}\text { Behavioral } \\
\text { boundaries }\end{array}$ & $\begin{array}{l}\text { Goal-setting } \\
\text { frames }\end{array}$ & $\begin{array}{c}\text { Power } \\
\text { distribution }\end{array}$ & $\begin{array}{l}\text { Cognitive change } \\
\text { readiness }\end{array}$ & $\begin{array}{l}\text { Founder legacy } \\
\text { fairness }^{2}\end{array}$ & \\
\hline Heimdall & High & High & High & High & High & 1.85 \\
\hline Nanna & High & High & Medium & High & High & 1.58 \\
\hline Frigg & High & Medium & Medium & Low & Low & -0.43 \\
\hline Balder & High & Medium & Low & Low & High & 0.40 \\
\hline Freyr & Low & Medium & Medium & High & Low & 0.92 \\
\hline Odin & Low & Low & Low & Low & Low & -0.47 \\
\hline
\end{tabular}

